\title{
Religious Education of Lifelong Learning in Taiwan Weixin Shengjiao I Ching University
}

\author{
Li-Yueh Chen, PhD \\ Weixin Shengjiao College \\ Chen-Mei Li, PhD \\ Weixin Shengiiao College \\ No.667, Ln. 705, Wenhua Rd., Nantou City \\ Nantou County 540, Taiwan
}

\begin{abstract}
From the mid of the 1980s to 1990s, the political and economic environment have been found an important change in Taiwan. Therefore, an embryonic form of new religion named Weixin Shengjiao was found in 1983. In 1994, The President of Republic of China Mr. Lee Teng-Hui declared the educational policy to address the importance of lifelong education. The founder of Weixin Shengjiao, Grand master Huan Yuan responded to UNESCO and the national educational policy for lifelong learning. In 1994, I Ching University was established as a pioneer of lifelong education in Taiwan. However, declining birthrate and population aging have impacted the education industry in Taiwan. This study uses the case study method and resource based view theory to find out the competitive advantages of I Ching University and explores how it offers an ideal religious education of lifelong learning to fulfill the vision of world peace.
\end{abstract}

Keywords: Religion education, Lifelong learning, I-Ching, Feng-Shui

\section{Introduction}

In the mid-1980s to the 1990s in Taiwan, there has been a critical change in the political and economic environment. In 1991, the President of the Republic of China, Mr. Lee Teng-hui, declared the abolition of the "Temporary Provisions Effective during the Period of Communist Rebellion". This makes Taiwan's politics more democratic. In 1996, the first direct Presidential election was held; in 2000, political party alternation took place for the first time. In the 1980s and 1990s, Taiwan actively promoted economic liberalization and developed technology-intensive and information industries. Meanwhile, Taiwan strived to become Asia-Pacific Regional Operations Center and the professional operations center for manufacturing, transportation and professional service. As a result, Taiwan's economy has gradually entered a mature stage. In the field of education, the Executive Yuan Education Reform Review Committee proposed "Education Reform: General Counsel Report" on October 2, 1996 suggesting increasing university enrollment capacity, founding high schools and universities extensively, and promoting multiple entrance program to ease the pressure to advanced study.

Under the pace of democratization, the government is becoming more open in religious and educational policies and allows people to create new religions and set up new universities as long as good social customs are not violated. Therefore, under this circumstance, the embryonic form of a new religion came into being in 1983. Later, the religion was named "Weixin Shengjiao" as it was well-developed. In 1994, President Lee Teng-hui made a clear policy statement on "lifelong education": "The idea of lifelong education is to confirm that everyone has his need for education in every stage of life and aims to establish a learning society". Therefore, the founder of Weixin Shengjiao, Grand Master Hunyuan suggested that everyone deserve a basic right of learning. In the same year, I Ching University was founded and began to offer lifelong learning to carry forward Chinese culture and to advocate I Ching learning. In the history of education in R.O.C., I Ching University is a pioneer promoting lifelong learning with its founding purpose of cultivating talents, revitalizing people's morals, refining ambitions, and creating universal harmony.

However, declining birthrate and population aging have impacted the education industry. The leaders and managers at all levels of educational institutes, from kindergarten to university and the national education authorities are all concerned about this issue and search for solutions. I Ching University mainly offers non-degreed lifelong education but is affected as well. However, even facing the changes and challenges in the educational environment, I Ching University can still break through adversity and develop into such a large-scale institute. It must have its competitive advantages. 
This study uses the case study method and resource based view theory to find out the competitive advantages of I Ching University and explores how it offers an ideal religious education of lifelong learning to fulfill the vision of world peace.

\section{Literature review}

\subsection{Resource based view}

Wernerfelt (1984) first proposed a shift in analyzing organizations from a focus of product-market to that of a resource position. He defined a resource to be "anything which could be thought of as a strength or weakness of a given firm" (p.172). Resource based view (RBV) is useful in determining whether a firm's strategy will create value and also enables the organization to conceive and implement strategies for improving efficiency and effectiveness (Barney, 1991). RBV focuses on the access or development of idiosyncratic resources and competencies that lead to competitive advantage which sustains over the long term. (Barney, 1991). Resources are classified as tangible (including financial and physical resources), intangible (including reputation, technology, and organizational resources), or personnel-based (including culture, training, commitment, loyalty and knowledge) (Grant, 1991). However, the researches on resource have been focused more specially on "strategic resources" (Amit \& Schoemaker, 1993). Strategic resources are those resources that (1) have value, such that they can leveraged to increase customer value or cut costs; (2) are rare, such that competitors do not have access to the same or a very similar resource to compete away the value; and (3) are difficult to substitute and (or) imitate, which allows the organization to stay ahead of competitors (Barney, 1991).

\subsection{Religious education}

What is so-called religious education? As to the word "religion", Grand Master Hunyuan states that "religion, not relating to gods nor spirits, not mysterious, is the development of each person's spirituality and wisdom. It is compassionate and inspires everyone's inner heart. The world will become peaceful when people are enlightened and realize that their hearts are the manifestation of gods and buddhas. The world will be peaceful because people respect each other."Grand Master Hunyuan claims that "Heaven and earth establishes (Zhong), sages set doctrines (Jiao) and all are generated, namely "religion" (Zhong Jiao). We educate in line with sages' enlightened experience and doctrines". Moreover, Grand Master Hunyuan instructed what so-called "education" is by a couplet posted Weixin Shengjiao Hsien Fo Temple, "a celestial being nets a basket; heart is the king of pure land of Buddha". He thinks "education" is magnanimous and realizes all phenomena. We must respect and value all beings as sages, teach them in accordance with their aptitude and help them fulfill their achievement and behave with great dignity. We also need to teach all beings to perceive each moment in the future till reaching enlightenment. Grand Master Hunyuan pointed out that "a celestial being nets a basket" means inviting all walks of life to contribute their wisdom to the society. Meanwhile, "heart is the king of pure land of Buddha" implies that pure land of Buddha is a palace of wisdom. Weixin Shengjiao is an open-minded platform for cultivating talents. Therefore, Grand Master Hunyuan proposed that the aim of I Ching University supported by Weixin Shengjiao is to raise and cultivate talented people. Grand Master Hunyuan states that Xian (賢) means the great inner wisdom embedded in everyone's heart. The idea of "raise and cultivate talented people" is to respect everyone in the world, cultivate them and treat them as sages. It does not matter if they are princes, military or political leaders, tradesmen or porters. Therefore, for the purposes of carrying forward dharma and benefiting all beings, we should accumulate wisdom and strive to cultivate, support and retain talents.

\section{The Religious Education and Competitive Advantage of I Ching University}

This study used the case study method and resource based view theory to study how I Ching University offers an ideal lifelong learning of religious education to fulfill the vision of world peace and finally find out its competitive advantages. This study found that the core of religious education offered by I Ching University lies in five kinds of education: (1) moral education, (2) life education, (3) environmental education, (4) filial piety education and (5) culture education. The philosophy of Liji, Liyun Datong (Book of Rites, Chapter of Great Harmony) is the core value of these five kinds of education. In 2007 Grand Master Hunyuan began to interpret Liji, Liyun Datong (Book of Rites, Chapter of Great Harmony) in a meditative way. He pointed out that Liji, Liyun Datong (Book of Rites, Chapter of Great Harmony) is Confucius' supreme heart method of ruling country, family and career. It is also a heart method for our inner uneasiness and dissatisfaction. Confucius realized the greatness of Liyun Datong (Chapter of Great Harmony); that is why it has been passed down to the present. Then, the Father of Republic of China, Mr. Chung Shan Sun promoted to the whole world. "Liji, Liyun Datong is a heaven way, a method of pacifying human mind, which is a truth derived from ancient sages' experience of enlightenment. It is an excellent classic for us to practice, to found a nation, and to fulfill world peace. It brings hopes to Chinese descendants in the future. Liji, Liyun Datong is great wisdom which points out the direction for governing a nation, and the method to manage our mind, family, career, society and nation. If everyone can understand Liyun Datong, I believe that the world will be peaceful." 
"Modern life and social phenomena are both inseparable from the word li (etiquette)". In Liyun Datong, etiquette is the main idea and the first priority. Li (etiquette) is applicable to managing our life, changingour destiny, and enhancing the harmony of society. Therefore, to establish everyone's dignity is the most important for us to carry forward the truth of Liyun Datong. The five core values of religious lifelong education established by I Ching University are elaborated as follows:

\subsection{Moral education}

In moral education, Grand Master Hunyuan argues that "morality is built on the basis of security and peace". This means that the problems in the family finance, such as unemployment and the financial difficulties in companies will result in safety problems and furthermore affect the whole society and country. Therefore, people's morality would be developed only if people feel safe and peaceful and make a good living. As said in Guan Yan Biography, "full food warehouse enables society to acquire etiquette; wealth enables men to be courteous". Therefore, in the year Guisi (2013), in the Weixin Shengjiao Jiujiu Religious Assembly, Grand Master Hunyuan preached the public: "the heart method of Weixin Shengjiao leads everyone to the path of peaceful mind by creating 'benefits' through I-Ching FengShui of cultural orthodoxy. You will have a clear conscience as long as your family and career are stable and safe. Realizing ourselves' inner Buddha quality (self-heart Buddha), stabilizing our family and bringing harmony to our surroundings are all the method of achieving Buddhahood and the Way".

This study found that I Ching University considers that business management is fundamental to people's livelihood in human economy. If an enterprise has a crisis, the society will become chaotic and have moral related problems. Therefore, I Ching University has established the world Taiwan business services association to serve enterprises. Grand Master Hunyuan points out if a company, a factory or a residential place follows the principles of Feng Shui, then the employees will have a secure life and finance, and thus be able to create a peaceful and prosperous society.

\subsection{Life education}

In life education, I Ching University teaches how to achieve peace of mind. Grand Master Hunyuan taught the public Liji, Liyun Datong (Book of Rites, Chapter of Great Harmony): "Etiquette promotes great harmony. Etiquette comes from trustworthiness, and vice versa. For cultivating oneself, raising a family, governing a country, and attaining the world peace, the most important driving force is etiquette. Without etiquette, there will be chaos in the family, society, company, and country". Etiquette is built on the basis of wisdom; therefore, a courtesy man will inspect his own heart and treat others with etiquette. That is the best way to calm one's mind. Grand Master Hunyuan points out: "Gui Gu Xian Shi Wang Chan Lao Zu (鬼谷仙師王禪老祖)said 'destiny, no destiny to be made, but only to follow the law of cause and effect, luck, no luck to be made, but only to be accumulated by merits, appearance, no appearance to be shown, but only to be reflected by heart'. This is a very profound philosophy. Blessing and merits are accumulated through self-cultivation and self-sufficiency. People born into the world should be thankful and full of gratitude. People should cherish and continue to manage their relationship, and establish good connection with others for future life. People should contribute to the worldly harmony and be kind. No one should be arrogant. Scholars, farmers, artisans, and businessmen all have their own strength, expertise and destiny. Everyone needs to do his duty and has devotion to learn. "Do not have merciless relationship with others nor bond to any enmity and hatred. A person must establish good relationship with others. He needs to understand that something good that he achieves is his responsibility; on the other hand, if he does wrong things, then he needs to reflect and repent. Reflection and repentance are not only the greatest assets within us, but also the source of vitality".

In order to implement life education, I Ching University organizes a program, "Teacher Counseling Camp" in summer vacation for school teachers from different levels of institutes all over the world. At present, the credit hours of the program have been recognized by The Senior Secondary School and Lower and Kindergarten Levels, the Ministry of Education, R.O.C. The life education of I Ching is the main axis of the courses. It aims to help the teachers understand more about themselves, learn how to teach in line with students' aptitude and guide them to the right path of life. The heart method of I-Ching Feng-Shui of Chinese culture is applied to help the teachers establish the right concept of life education and conduct student counseling sessions. The previous related studies have indicated that studying I-Ching has significant effects on improving teachers' performance on teaching and student counseling after they participated in a seminar of I Ching Life Education (Chen, Li \& Lin, 2016).

\subsection{Environmental education}

This study found that the environmental education of the I Ching University is "the education of I-Ching and FengShui", emphasizing that all the construction in natural environment must meet the principles of Feng-Shui. It teaches the public to respect nature. Grand Master Hunyuan stated that "People may not believe in Feng-Shui, but actually have been shrouded in the bliss of Feng-Shui". Grand Master Hunyuan interpreted Liji, Liyun Datong (Book of Rites, 
Chapter of Great Harmony) in a meditative way and pointed out: "mountains and rivers are teachers. All things are our teachers as well. The presence of mountains and rivers of the earth is to educate us. We should be thankful to mountains, rivers, air, Feng-Shui, etc for their teachings. All changes in the mountains and rivers have deep connotations. We need to be part of nature, into nature, and to realize nature. That is education and learning". Hence, the environmental education of I Ching University considers that human beings living between heaven and earth should express their gratitude to nature and treat nature with a modest talent's attitude suggested in I-Ching.

Grand Master Hunyuan said: "Now the social chaos is caused by wrong Feng-Shui. Today, the Chinese cultural orthodoxy - I-Ching and Feng-Shui is the driving force for peaceful mind and stable family, society and country". Therefore, for environmental education, I Ching University offers the summer seminar of Architecture Design and Feng-Shui to students from the departments of architecture, landscape, civil engineering, interior design, urban planning or related departments in the world every year. After the one-month intensive training course, prospective architects, civil engineers, interior designers, or public government urban planning servants are expected to understand the importance of I-Ching Feng-Shui study to the environmental protection on the earth. Meanwhile, the university hosts the study program of architectural space and aesthetic design for the project, 'Teachers Participating in Public or Private Enterprise Service' sponsored by the Ministry of Education for the vocational high school teachers. After studying in the camp, school teachers, especially in the fields of construction, landscape and interior design will acquire the essence of I-Ching Feng-Shui and apply it to their teachings to help students establish the idea of protecting the earth.

\subsection{Filial piety education}

Filial piety connects family which develops into a clan, society and country. It is the most important asset of the Chinese nation. The concept of filial piety of the Chinese nation began with respecting ancestors and was inferred from the ancestral worships. Then, the respect was extended from the deceased ancestors to the beloved parents. ErYa, Shi Xun says "being nice to parents is filial piety". In I-Ching, ShuoGua, it denotes "Qian, heaven, is called father; Kun, earth, is called mother". Xiao Jing, Sheng Zi Zhang says "of all (creatures with their different) natures produced by Heaven and Earth, man is the noblest. Of all the actions of man there is none greater than filial piety". In summary, filial piety is a natural expression of children to their parents, showing the spirit of repaying their origins. In Xiao Jing, Kai Zong Ming Yi Zhang, Confucius says "now filial piety is the root of all virtues, and the stem out of which grows all moral teachings". It is obvious that filial piety is the foundation of all morality and is the source of all education.

This study found that I Ching University held the "Chinese Jointed Ancestors Worship Ceremony" to implement filial piety education and to lead the public to express their retrospection, repentance and recollection to their ancestors. The ceremony is to pacify our ancestral spirits and release the bond of enmity. The ultimate goals are to help Chinese ancestral spirits return to Nantian Pure Land and be reborn to Western Pure Land, and eventually to achieve universal peace. Therefore, the study found that I Ching University had held "Chinese Jointed Ancestors Worship Ceremony" on January 1, 2004 for the first time, followed by 2005, 2006, 2008, 2009, 2012, 2013, 2014, 2015, 2016, 2017 in National Taiwan Sport University Gymnasium. According to the author's field observation, spirit tablets and offerings were set up in the altar of "Chinese Jointed Ancestors Worship Ceremony" for Chinese ancestors of 15,615 surnames, the dead in 3,762 wars, 917 emperors of Chinese dynasties, 124 Japanese emperors and their dependents since Xu Fu in Qin dynasty, considered the Chinese blood, migrated to Japan, 202 kings and their dependents since the descendants of Chiyou, one of the Chinese three ancestors, migrated to Korea, and the dead in 816 wars in the world. I Ching University held religious rituals to call the spirits to the ceremony to receive their descendants' offerings and worship.

\subsection{Cultural education}

In the promotion of cultural education, I Ching University is committed to promoting 'Children's Classic Reading Education' (兒童讀經教育 Ertong Dujing Jiaoyu). The so-called Du Jing (literally, read classic) is the abbreviation of Du Song Jing Dian (literally, read recite classic book). Du (reading) means 'learn by heart' and implies reading longlasting and valuable classics. It is a kind of teaching process which takes advantage of children's good memory and enables them to recite classics by reading repeatedly (Wang Caigui, 1994).

In the promotion of cultural education, I Ching University is committed to "children's I-Ching study". I Ching University focuses on children's learning of I-Ching to develop children's potential great wisdom. Therefore, I-Ching has been planned in Children's basic education, and the university has established 'Center of Children's I Ching Study'. Grand Master Hunyuan believes that basic education is necessary to strengthen a country and harmonize a society. The primary education is the beginning of formal education for everyone. The success or failure of school education also affects the future of a country. Chinese culture-I Ching, is the key and the only way to cultivate inner wisdom. It can be seen from previous studies that children significantly improved their temperament, enhanced their lifelong learning abilities and inhibited their bullying behavior (Chen, Li, Lin \& Lin, 2015). 


\section{The Competitive Advantage of I Ching University}

The competitive advantage of an organization is a powerful engine to promote itself. This study adopted the definition of organizational resources, classification and elements proposed by Grant (1991) and Barney (1991) and found that I Ching University has five competitive advantages, which are: (1) a complete education system, (2) Chinese cultural orthodoxy-Weixin Dao Zang (唯心道藏), (3) complete faculty education system, (4) complete learning network, (5) the application of media and information technology. Therefore, I Ching University has the five competitive advantages which enable itself to promote the five core values of the religious education. The five competitive advantages are as follows:

\subsection{Complete education system}

Grand Master Hunyuan stated that "Weixin Shengjiao employs educational system and cultural documentation to educate the public for the goal of cultivating talents. Now, I Ching University has established a complete education system which offers lifelong education, academic education, and international education. I Ching University has integrated the ideas of Confucianism, Buddhism and Taoism into I Ching Feng Shui of Chinese culture. The university offers lifelong education, academic education and international education to accomplish the cores of Weixin Shengjiao's religious education-moral education, life education, environmental education, filial piety education and cultural education to achieve the goal of world peace by 'spiritual practice for the nation' and 'pray for the people'. According to a study which investigated the students of I Ching University who participated in the lifelong learning of religious education, the empirical results indicated that the main motivations of learning were their intention of social contribution and interest of knowledge. Their motivations brought significant improvement on their family and life satisfaction, and the wellbeing (Chen, Li \& Lin, 2015; Chen, Li \& Lin, 2015).Therefore, from this viewpoint, no other general university has established such a complete educational system as I Ching University has. That is the advantage of 'value and rare' suggested by RBV.

\subsection{Chinese cultural orthodoxy-Weixin Daozang}

Weixin Daozang is the teachings of Wang Chan Lao Chu and has been preached by Grand MasterHunyuan since 1982. Grand Master Hunyuan's teachings have been assembled into books and published. Till October 2012, there have been more than 15,615 books; the teachings still continue and are being assembled. Grand MasterHunyuan pointed out: "the lineage of Weixin Daozang began with Kunlun civilization, about fourteen thousand and five hundred years ago..... Today, the wisdom of Danzang is the heavenly secrets manifested in the world in $21^{\text {st }}$ century. The Gui Gu Immortal Master Wang Chan Lao Chu descended to combine with Human to reorganize Chinese cultural orthodoxy and create a beacon to the world peace". As a result, Weixin Daozang lays a solid foundation for lifelong religious education. Therefore, from this point of view, in the Chinese cultural orthodoxy - the inheritance of the heart method of I-Ching Feng-Shui, I Ching University documented the wisdom of the Chinese ancient sages, which is referred to Grand Master Hunyuan's statement: "Weixin Shengjiao employs cultural records to educate the public and to raise talents". I Ching University has complete self-developed teaching materials; from the perspective of quantity and scope of coverage, no other educational institute can compete. This advantage is so-called 'difficult to substitute' of Resource-Based View.

\subsection{Unique and complete faculty education system}

In order to cultivate the faculty of I Ching University to implement the educational philosophies of "my doctrine is that of an all-pervading unity" and "one pure lineage". In November 1990, Grand Master Hunyuan started cultivating talents through "academy education" and later established Weixin master program, Weixin doctoral program and faculty education program for teacher training. The faculty members of I Ching University are selected from the students who study in its own educational system. Then, the selected students will be cultivated before engaging in teaching. The faculty cultivation of I Ching University is different that of general university outside the world. The faculty members of a general university usually earn degrees first, and then start their teaching career. That is the advantage of 'uniqueness' mentioned in RBV.

\subsection{Complete learning network}

I Ching University, with the concept of "Taiwan as a university, a district or county as a branch, a living room as a classroom, and a television as a blackboard", practices the idea of religious lifelong education and hopes to promote Chinese culture all over Taiwan and the world. "Community" is the most basic living unit of human beings; it is neither abstract nor theoretical. 
Each community has its unique lifestyle and humanities. Community life is a kind of sharing, communion and cogovernance. The community is a group of people who live in a certain geographical area, and have a common relationship, social assistance and service system (Shu Cheng, 1998).

Therefore, this paper found that I Ching University had set up the community education to make up for the current lack of school education in order to implement the lifelong learning advocators' words, "everyone learns everywhere from time to time, and learns everything". In 1995, the lifelong education started with learning within communities and gradually was expanded to regional classes. This is likened to the whisk in Wang Chan Lao Chu's hand of which each thread is emitted to each area. That means 'dharma', the wisdom of ancient Chinese sages and the heart method of IChing Feng-Shui of Chinese culture, is propagated according to local humanities and socio-economic characteristics. The lifelong education has carried forward the heart method of Feng Shui of Chinese culture. Up to now, I Ching University has 42 learning hubs in Taiwan and 33 classrooms in communities. Overseas classrooms have been set up in Hong Kong, Vietnam, Japan, Spain, Los Angeles and New York, Toronto, Canada, etc.Up to now, I Ching University has more than 60,000 students totally. Therefore, in the point of view, no other university delivers education to all communities as I Ching University does. This is 'value and rare' mentioned in RBV.

\subsection{The application of media and information technology}

Meanwhile, Weixin TV station has been founded in the volunteering career system, broadcasting 24 hours a day. New it has developed into a network TV station. All courses offered by I Ching University can be watched globally as long as there is an internet service. The concept of open educational resources was presented in the 2002 UNESCO International Conference Forum. It is mainly about organizing high-quality teaching materials and resources into digital materials on the Internet for the public to share and learn without any charge. In order to help overseas students who cannot learn face to face in the classroom, I Ching University has established Cloud Classroom (Cloud classroom http://mbsb.tw). Overseas students can register online and study without time constraints. The idea of setting up Cloud Classroom of I Ching Feng Shui and Weixiin TV station is consistent with UNESCO's thinking model and educational resource sharing. It will promote the understanding and recognition of Chinese culture, help to create a harmonious society and fulfill the world peace. From this point of view, there is no other university does the way I Ching University does in terms of utilizing its resources of media and information technology to extend its education abroad. This is the value and uniqueness of the resource-based view.

\section{Conclusion}

In conclusion, the paper found that I Ching University is committed to carrying forward I Ching Feng Shui of Chinese culture all over Taiwan and the world to reach the ultimate goal of social tranquility and the world peace. This is in line with UNESCO's national education policy for lifelong learning and learning society. Likewise, the goal of I Ching University is the same as that of UNESCO's international lifelong education, 'world peace'. Weixin Shengjiao I Ching University utilizes its five competitive advantages. This study found that Weixin Shengjiao combines I Ching Feng Shui of Chinese culture with Confucianism, Buddhism, Taoism and the thought of Chinese hundred schools. Weixin Shengjiao implements and applies them to the core of religious education - moral education, life education, environmental education, filial piety education and cultural education in terms of the three dimensions of lifelong learning at I Ching University: lifelong education, academic education and international education.

Grand Master Hunyuan pointed out that the education of I Ching University is broad, providing human beingsa consistent way to back to Pure Land for each stage, from birth, childhood, adolescence, early adulthood, midlife, mature adulthood late adulthood and finally to death. Therefore, the religious education of I Ching University aims to develop human virtue and wisdom to let everyone live, learn, work and grow in a peaceful and safe environment. That is the ultimate goal of I Ching University, raising and cultivating talents. Finally, the purpose of I Ching University is to nurture talents. Its ultimate goal is to build a polite society as described in Liji, Liyun Datong (Book of Rites, Chapter of Great Harmony) which says Thus evil scheming is repressed, and robbers, thieves and other lawless elements fail to arise. So that outer doors do not have to be shut. This is called the Age of Great Harmony". This is the true meaning of the religious education of I Ching University.

\section{Reference}

Amit, R. \& Schoemaker, P.(1993). Strategic Assets and Organizational Rent.Strategic Management Journal, 14(1), 33-46.

Barney, J. (1991). Firm Resource and Sustained Competitive Advantage. Journal of Management, 17,99-120. 
Chen, L. Y., Li, C. M. \& Lin, P. C. (January, 2016). The Study on I-Ching Life Education Curriculum, Learning Motivation and Effectiveness in Chinese Culture: A Case of I Ching University. The IAFOR International Conference on Education - Hawaii 2016, Honolulu, Hawaii, U.S.A., The International Academy Forum.

Chen, L. Y., Li, C. M. \& Lin, P. C. (October, 2015). The Effect of I-Ching Education on the Temperament of Elementary School Children, Lifelong Learning Capability, and Bullying Behavior. The Asian Conference on Education 2015, Kobe, Japan, The International Academy Forum.

Chen, L. Y., Li, C. M. \& Lin, P. C. (October, 2015). Motivation for Learning I-Ching among Adult Lifelong learning in I-Ching University. The Asian Conference on Education 2015, Kobe, Japan, The International Academy Forum.

Grand Master Hun Yuan (2008).Zen version of interpretation for the "Chapter of Great Harmony in the Operation of Etiquette" in "Book of Rites", (Volume VII).Taichung: Wei Xin Zong Cultural Communication Co. Ltd.

Grand Master Hun Yuan (2008).Zen version of interpretation for the "Chapter of Great Harmony in the Operation of Etiquette" in "Book of Rites", (Volume VI).Taichung: Wei Xin Zong Cultural Communication Co. Ltd.

Grand Master Hun Yuan (2008).Zen version of interpretation for the "Chapter of Great Harmony in the Operation of Etiquette" in "Book of Rites", (Volume V).Taichung: Wei Xin Zong Cultural Communication Co. Ltd.

Grand Master Hun Yuan (2008).Zen version of interpretation for the "Chapter of Great Harmony in the Operation of Etiquette" in "Book of Rites", (Volume IV).Taichung: Wei Xin Zong Cultural Communication Co. Ltd.

Grand Master Hun Yuan (2008).Zen version of interpretation for the "Chapter of Great Harmony in the Operation of Etiquette" in "Book of Rites", (Volume III).Taichung: Wei Xin Zong Cultural Communication Co. Ltd.

Grand Master Hun Yuan (2008).Zen version of interpretation for the "Chapter of Great Harmony in the Operation of Etiquette" in "Book of Rites", (Volume II).Taichung: Wei Xin Zong Cultural Communication Co. Ltd.

Grand Master Hun Yuan (2007).Zen version of interpretation for the "Chapter of Great Harmony in the Operation of Etiquette" in "Book of Rites", (Volume I).Taichung: Wei Xin Zong Cultural Communication Co. Ltd.

Grant, R.M.(1991).The Resource-Based Theory of Competitive Advantage: Implications for Strategy Formulation,California Management Review,33, 114-135.

Laudon, K. C. \& Traver, C. G. (2014). E-commerce 2014: Business, technology, society(Tenthed.). Boston, USA. Addison Wesley.

Shu, C. (1998).Community and Community Development.Taipei, Taiwan: Chen Chung Book Ca., LTD.

Wernerfelt, B.(1984). A resource-based view of the firm. Strategic Management Journal,5(2),171-180.

Zhu, E.\&Baylen, D. (2005). From learning community to community learning: pedagogy, technology and interactivity. Educational Media International, 42(3), 251-268.

\section{Contact email:}

Li-Yueh Chen Liyueh@wxc.org.tw

Chen-Mei Li Ljm.dh68@wxc.org.tw 